\title{
Felsefi Bir Söylem Biçimi Olarak Susku*
}

\author{
VEFA TAȘDELEN ${ }^{*}$
}

\begin{abstract}
ÖZ
Felsefe, hep söylemek eylemi üzerine kendini inşa eder, söylemek eyleminde kendini gerçekleştirir. Söylemeyen, söylemeye eğilim duymayan bir felsefe düşünemeyiz bile. Susku hali, zaman zaman felsefenin gündemine girmiştir. Bunun en ileri örnekleri Kant, Kierkegaard ve Wittgenstein'da görülebilir. Bunlar öylesine anlamlı suskulardır ki, adeta felsefenin temel soruları karşısında verilmiş en sahih cevaplardır. Özellikle metafizik konular söz konusu olduğunda -ki buna ölüm de dâhildir- felsefenin, derin susku sularına gömüldüğü görülebilir. Sorun şudur: Susku, sözü bitirir mi yoksa yeni bir konuşma mı başlatır? Susmak, gerçekten susmak mıdır, yoksa Rilke'nin dediği gibi “yeni bir başlangıç, yeni bir işaret ve yeni bir değişim” midir? Sustuğumuz zaman, konuşmayı bitirmiş mi oluruz, yoksa asıl konuşma o zaman mı başlar? Eğer susku da bir konuşma tarzıysa, felsefi bir söylem biçimi olarak ortaya çıkma durumu söz konusu olabilir. Bu bağlamda sorulabilecek bir başka soru da şudur: Ölümün getirdiği ebedi susku, felsefi değerde midir?
\end{abstract}

Anahtar sözcükler: Felsefe, söylem, susku, ölüm

$\beta^{u}$

zamana değin karşımıza hep konuşan, sorular soran ve derin sorgulamalarda bulunan bir alan olarak çıktı felsefe. Kimi zaman hayranlıkla dinledik onu, kimi zaman anlama yetimizin sınırlarını zorlayarak. Bizi yordu belki ama haz da verdi; düşüncemizin sınırlarını da genişletti. Bildiğimiz şey, nihayetinde kendi faniliğimiz de olsa, bilmenin anlamıyla aydınlandı hayatımız. Verdiği haz, sıradan bir haz değil, bilmenin ve anlamanın sevinci ve özgüveni gibi bir şeydi. Özlerden, genel ilkelerden, nihai hakikatlerden söz ederken anlaşılmaz

\footnotetext{
* 7-9 Ekim 2015 tarihlerinde IV. Ilgaz Felsefe Günleri kapsamında Kırıkkale Üniversitesi'nde düzenlenen "Felsefe ve Ölüm Sempozyumu"nda sunulmuştur.

** Prof. Dr., Yıldız Teknik Üniversitesi, Eğitim Bilimleri Bölümü/İSTANBUL

E-posta: vefa@yildiz.edu.tr
} 
geldiği de oldu; ama hangi durumda olursa olsun hep konuşurken, hep söylerken gördük onu.

Felsefe konuşmayı sever, ancak susmayı da sever; suskunun da felsefi bir tutum olarak ortaya çıktığı durumlar vardır. Böyle zamanlarda susku tıpkı konuşmada olduğu gibi, felsefi bir değerde ortaya çıkar. Suskunun bir söylem biçimi olması, kaçınılmaz olarak ona bir anlam atfedildiğini, ne kadar susku da olsa, gizil bir söz dizimine sahip olduğunu gösterir. Bu makalede, "Acaba susku da felsefi bir konuşma, felsefi bir söylem biçimi olabilir mi; eğer olabilecekse bunun imkânı nedir" sorusuna cevap aranacaktır. Konu, daha çok Kant, Kierkegaard ve Wittgenstein felsefelerindeki susku çerçevesinde ele alınacaktır. Bu bağlamda cevap aranacak sorular şunlardır: Suskunun felsefe tarihi içindeki yeri, filozofların susku konusundaki görüşleri nedir? Filozoflar, belirli konular karşısında gösterdikleri susku durumu ile örtük bir konuşma mı başlatırlar? Susku durumu, felsefede bir söylem olabilir mi? Susku, felsefi bir değerde ortaya çıkabilir mi? Son olarak ebedi bir susku durumu olan ölüm, nihai hakikatleri aramayı iş edinen filozoflar açısından ne ifade eder? Bu ebedi susku, söyledikleri ve söylemedikleri ile felsefi bir değerde midir?

\section{Susku ve Felsefe}

Hangi durumda olursa olsun hep konuşurken, söylerken görürüz felsefeyi. Felsefe demek, "söz" demektir; "söylemek" ve "konuşmak" demektir. Felsefe bir söz ve dil varlığıdır; bir söz ve dil sevgisidir. Bilgelik sevgisi, dil sevgisiyle başlar. Felsefe, söze bel bağlar; kendi varlığını sözün varlı̆̆ında kurar. Söz felsefenin yapıtaşıdır, hücresidir; onun söz alanından başka basabileceği, kendini gerçekleştirebileceği bir kara parçası yoktur. Felsefe sözde cisimleşir, sözle cisimleşir; sözde varlığa kavuşur. Bu nedenle felsefe sözü genişleten, zenginleştiren, özleştiren, derinleştiren bir etkinliktir. Yalnız kendi çağımızla, kendi koşullarımızla sınırlı değildir felsefenin konuşması, geçmiş ve gelecek kuşaklarla da konuşur. Felsefe bu diyalogda gerçekleşir. Filozof, kendisinden önceki filozoflarla diyaloğa geçer; bu şekilde felsefesinin bir bağlam ve gelenek içinde ortaya çıkmasını sağlar. Ama sadece geçmiştekilerle konuşmaz, gelecektekilerle de konuşur ve asıl onlara seslenir.

Şairler, romancılar, öykü yazarları zaman zaman konuşarak susan, zaman zaman susarak konuşan insanlardan söz ederler. Peyami Safa, Fatib-Harbiye'de, Şinasi'ye hitaben Neriman'a şöyle söyletir: "Ben sustuğum zaman bile sen beni anlamalısın” (2000: 86). Gerçeği söylemek gerekirse, gündelik hayatta, susku hali ile ortaya çıkan anlamllık durumlarına biz de tanıklık ederiz: susarak konuşanlara, susarak soru soranlara, susarak cevap verenlere, susarak tepki gösterenlere rastlarız. Peki, felsefede susmanın anlamı ne olabilir? Bir şey söylemeden çok şey söylemenin, çok şey söylemeyi kastetmenin anlamı ne ola- 
bilir? Filozofun susması ne anlama gelir; bu susku anlaşılabilir bir şey midir? Bir ilgisizlik ve düşünemezlik, bir sorunsuzluk ve dertsizlik durumu mudur; sessizliğin derin sularına gömülüp gidivermek gibi bir şey midir?

Felsefede ortaya çıkan susku durumu konuşmayı bitirmez, çoğaltır. Filozof tıpkı konuşmada olduğu gibi dille susar, dilde susar. Felsefedeki susku, anlamsızlık ve salt doğal sessizlik hali değil, bir anlam durumudur. Bazen bir sorudur, bazen bir cevap; bazen bir yöntemdir bazen bir tutum. Felsefi suskuda dil sussa da bilinç susmaz; sorunu yok saymaz, görmezlikten gelmez. Felsefe merak ve hayret eder, konuşur; düşünür. Susmak kimi zaman düşünmeye başlamaktır. Bu durumda, susma ile yoğunlaşan ve yola giren felsefe, konuşarak, söyleyerek yol alır. Suskunun bir söylem biçimi olması, kaçınılmaz olarak ona bir anlamın atfedildiğini, dolayısıyla, ne kadar susku da olsa, örtük bir söz durumu olduğunu, susku ile bir anlamın kastedildiğini gösterir.

Peki, her susku felsefe midir? Bir suskunun felsefi değerde olabilmesi için sahip olması gereken özellikler nelerdir? Bir suskunun felsefi değerde olabilmesi için ne söylemesi gerekir, nasıl söylemesi ve ne kadar söylemesi gerekir? Kuşkusuz her konuşma felsefe olmadığı gibi, her susku da felsefi değerde değildir. Konuşmadan konuşmaya nasıl ki fark varsa susmadan susmaya da fark vardır. Susku bazılarında konuşma, bazılarında soru, bazılarında cevap, bazılarında bir düşünmeme durumudur. Suskunun felsefe olabilmesi için, öncelikle söylemesi, bir söz ve anlam durumunu kastetmesi gerekir. Bunlar öylesine anlamlı durumlarıdır ki, âdeta varoluşun temel soruları karşısında verilmiş en sahih cevaplar gibidir. Özellikle metafizik konular söz konusu olduğunda -ki, buna ölüm de dâhildir- felsefenin, son yüzyıllarda derin susku sularına gömüldüğü görülebilir.

\section{Felsefi Bir Söylem Biçimi Olarak Susku}

Suskunun felsefi söylem olduğunu söylemek aşırı bir iddiada bulunmak olarak görülebilir. Ancak düşünce tarihine baktı̆̆ımızda, onun felsefi bir tutum olarak ortaya çıktığını görebiliriz. Samsatlı Lukianus, Pythagoras'tan söz ederken, onun, felsefeye giriş yapmak isteyenlere beş yıllık bir susku dönemi önerdiğinden söz eder (Lucian 1919: 181). Parmenides, kendisi hakkında konuşulamayan bir "var-olan"dan söz ederken, sözün katılaşarak bir susku durumuna doğru evrildiğini görebiliriz (Kranz 1984: 76). Gorgias ise üç basamaklı bir susku sarmalından söz eder: "Varlık yoktur, varsa da bile bilinemez, bilinse de başkalarına bildirilemez"(Kranz 1984: 197; Platon 1989). "Yaptığım şey gençlerin ruhundaki soylu düşünceleri doğurtmaktan ibarettir” diyen Sokrates’e gelince: $\mathrm{O}$ da kendisi konuşmaz, konuşturacak ve bu şekilde kendisiyle kendi düşünce yollarını aralayacak kişiler arar (Platon 1990: 24, 27, 28, 44). Ancak yine bu susku tutumundan, varoluşun temel sorunları karşısında insan zih- 
ninin sınırlı ve yetersiz bir durumda olduğu sonucu çıkarılabilir. Diyalogları bir çözümsüzlük ve belirsizlik (aporia) ile biten Platon felsefesinde de suskunun engin kıyıları görünmeye başlar. Soru, cevap bulamadan geri döndüğünde, düşünme sözü bitirdiğinde, susku, yeni yolları, yeni yolculukları esinler. Tanrı'ya, "İnsan, senin hakkında ne söyleyebilir kì? Hiçbir şey; çünkü suskudur en güzel konuşan” diye yakaran Augustinus da suskunun bir başka sayfasını açar. Zira dünyasal dil, aşkın (transcendent) olanı kavrayacak nitelikte değildir; kavramaya kalkıştığında, pagan örneğinde olduğu gibi, dünyasal niteliklerle donatılmış kanlı canlı, güçlü kuvvetli bir tanrı tasavvuruna doğru eğilim duyar. Böylece aşkın olan salt içkin bir varlık hâline dönüşür. Mevlâna da Mesnevî̀de Augustinus'la benzer bir duyarlılığ geniş; söz manaya daima kifayetsiz. Onun için Peygamber 'Tanrıyı bilenin dili tutulur' dedi. Söz usturlaba benzer. Usturlap göğ̈̈, güneşi ne kadar bilebilir ki?” (1988: 131). Simurg'a erişmek uğrunda, vadileri aşan kuşların hikâyesini anlatan Mantık al-Tayr'da da, Mevlâna'nın üstadı Attar, kuşların dilinden şöyle katılır suskuya:

Bundan sonra kimse sırra vakıf değildir. Çünkü orası ağyarın bulunacağ1 yer değil ki! Bu hususta kim bir şey söyler, bu sözü de kim duyar, işitirse adeta o hali kör görmüş söylüyor, o sözleri sağır dinlemekte! Ben kim oluyorum ki bunu anlatayım? Oraya varmadan nasil anlatayım? O makamın dışında kalmışım ben, bari susayım! Bu makamda sükûttan başka ne yapılabilir ki? Dil kilıcının gevheri, ancak sükûttur. Bir an bile bundan başka bir şey olmasına imkân yoktur. Susanın da on taneden fazla dili var, ama yine de susmakta. Susmaya âşık olmuş sanki! (1990: 198)

Kant’a gelindiğinde, Tanr1 ve ruhun ölümsüzlüğü, zamanın ve evrenin sonsuzluğu gibi metafizik konular, anlama yetisinin sınırları içinde anlaşılabilecek konular değildir. Bununla birlikte, insan akli, sürekli bu konularda konuşmak için eğilim duyar; düşünce tarihi içinde ortaya çıkan Tanrı kanıtlamaları bunun göstergesi gibidir. Kant'a göre insanın duyularına açık olan fenomenal alandan insanın anlama yetisine kapalı olan numenler alanına geçiş, insan aklının bir sıçramasıdır. Kişi, anlama yetisinin sınırı olan fenomenal alanın dışında bir bilgiye erişemez. İnsan kendine özgü biricik aklını yitirmek istemiyorsa bu sıçramayı yapmamalıdır. Kierkegaard ise karşıt bir tutumla bizden ısrarla bu sıçramayı yapmamızı, tıpkı İbrahim gibi riske girmemizi, bireyin evrensel olandan yüceliğinin bu risk ve sıçrayışta, absürt ve paradoksta, bu büyük tutkuda olduğunu söyler; çağdaş felsefeye taze bir soluk gibi getirdiği "birey", "öznellik" ve "varoluş" temaları, felsefesini örneklediği kavramsal kişiliklerden biri olan Hz. İbrahim'in şahsında ele alır. Buna göre, bireyin yaşadığı öznel deneyim, tıpkı Pascal'ın "yapayalnız ölürüz” özdeyişinde olduğu gibi, başkalarına kapalıdır. Bu görüş, daha sonra Heidegger'de, ölümün şahsiliği teminde yinelenir. 
Kierkegaard, suskuyu hemen her vesile ile söz konusu yapar. Ona göre suskunluk anı, içebakışın anıdır. Aksi halde konuşma insanı saklamaz ve giderek gevezeliğin içine batırır. Kierkegaard'un, kendisiyle Korku ve Titreme'yi yazdığ1, yazarlık hayatı boyunca kullandığı çeşitli müstear isimlerinden biri de "Suskun Johannes” anlamına gelen “Johannes de Silentio"dur. Söz konusu çalışmada, Hz. İbrahim'in durumu, üzerinde konuşulacak ve söze dökülecek nitelikte ortaya çımaz. Bu nedenle susku, daha uygun bir iletişim biçimidir ve İbrahim kendi durumunu suskunun diline emanet eder; zira ortada iletilebilecek, dilin nesnel ve evrensel potasına dökülebilecek bir anlam durumu bulunmaz. İbrahim, yanında oğlu ile birlikte, ona bir kelime bile söylemeden Moriah dağına doğru yolculuğa çıktığında, onun bu durumunu kim anlayabilir? İbrahim, bireydir; birey olduğu için evrensel olan karşısında yücedir. İman şövalyesinin durumu, trajik kahramanın, söz gelimi kendi toplumunun kurtuluşu için kızı Iphigena'yı tanrılara kurban veren, etiğin evrensel, anlatılabilir ve anlaşılabilir nitelikteki dili içinde bulunan Agamemnon'un, durumundan farklıdır. Etik, evrensel bir dil kullanır. Bu alanda kişi, anlaşılacağından emin olarak insanlara kendini anlatabilir; eyleminin gerekçelerini sunabilir. Ancak İbrahim'in durumu, etiğin evrensel kategorilerine aktarıldığında, bir oğul katili olarak ortaya çıkması muhtemel, hatta kaçınılmazdır. Zira etik, ondan, oğlunu korumasını, besleyip büyütmesini ister; bu, bir baba olarak onun ödevidir. Kierkegaard, varoluşun evrensel dile çevrilemezliğini, dile dökülemezliğini, varoluşsal deneyimdeki bireysellik ve öznellik durumlarını şu şekilde ifade eder: "Ĕger İbrahim, son anda İshak'a (İslamiyet'te, İsmail), 'Sen (kurban) edileceksin' deseydi, bu sadece bir zayıllık olurdu. Mademki, konuşabilirdi, çok daha önce konuşmalıydı... Ve eğer bunu yaparsa, trajik kahraman kadar bile olamazdı" (2002: 102). Trajik kahraman Agamemnon, etiğin evrensel dili içinde bir sahnededir; ailesi ve toplumu tarafından alkışlanabilir ya da lanetlenebilir bir konumdadır; öznelliğin ve bireyselliğin şahsında örneklendiği iman şövalyesi Hz. İbrahim ise, bu evrensel dilin dışındadır. Eğer kendi durumunu açıklayacak olsa, eylemini gerekçelendirecek ve kendi durumunu aşikâr kılacak cümleler kursa, o zaman eylemini etiğin evrensel diline tercüme etmiş olur. Söz alanında İbrahim'in durumunu anlamlı ve anlaşılabilir kılacak bir karşıllı yoktur. Ona bir karşılık bulmaya çalıştığımızda farklı bir durumu ifade edecek; bu da yanlış bir çeviri olacak, İbrahim, etiğin nesnel ve evrensel dilinde bir oğul katili olarak ortaya çıkacaktır. Etiğin teolojik olarak askıya alındığı bu durumu anlamlı kılan dil, konuşmanın değil suskunun dili olacaktır. Görünüşte Suskun Johannes onun öyküsünü anlatmaktadır, ama aslında bu anlatı da giderek bir susku durumuna doğru evrilmektedir.

Felsefi suskunun, en önemli temsilcilerinden biri de, çăgımız filozoflarından Wittgenstein'dır. Wittgenstein, felsefi söylemin sağlıklı bir yapıya kavuşabilmesi için, tıpkı Kant'in fenomen ve numen ayrımında olduğu gibi felsefi olarak 
“üzerinde konuşulabilen” ve “üzerinde konuşulamayan” ayrımı yapar. İlk dönem felsefesini yansitan "resim kuramı"nda, Kant'ın tutumunu sürdürür ve dilin evrenini, tıpkı Kant'ta olduğu gibi fenomenal alanla sınırlar ve şöyle der: "Felsefenin doğru yöntemi aslında şu olurdu: Söylenebilecekler dışında hiçbir şey söylememek" (1961: 150). Susku, hakkında konuşulamayanı yadsımaz, aksine evetler, inkâr etmez, kabul eder; Kant'ta da numenal alan aynı konumda bulunur. Bir şey vardır ve o hakkında konuşulabilecek bir şey değildir; çünkü dilde ve insanın algı sınırları içinde bir karşılığı yoktur. Burada konuşarak felsefe yapmanın imkânı tükenmiştir ama bir başka yol açılır: Susarak felsefe yapmak ya da susarak felsefenin ötesine geçmek. Bu durumda sükûttan sonra da felsefe bitmez, devam eder. Nitekim Wittgenstein'ın, "Üzerinde konuşulamayanlar hakkında susmak gerekir” önermesi, Bozkurt'un da işaret ettiği gibi, insanın üzerinde hiçbir şey söyleyemeyeceği bir dünyanın var olduğunu anlatmaya çalışan metafizik bir ifade olarak da görülebilir (1995: 236). Dolayısıyla felsefe bir kez başlamışsa, susmakla bitmez; olsa olsa başka bir evreye geçer ve biz susku durumu bitene kadar, sanki bir tünele girmiş gibi oluruz. Ancak bu yine de felsefenin yol almasi, yolda olmasi demektir.

Burada bir benzerlik de oluşturulabilir; o da suskunun, kimi durumda Kant'ın "yüce" (Erhabenheit) kategorisi ile bir benzerlik içinde olduğudur. Kant, insanın algı sınırını aşan sanatsal durumları "yüce" kategorisi ile nitelemişti; benzer şekilde suskuda da, kavrama gücünü aşan, anlama yetisinin ötesine geçen bir durum karşısında gösterilen bir susku söz konusudur. "Yüce", nasıl ki bir kategori ise, susku da bir kategori olmalıdır. Karşılaşılan şey konusunda bazen sadece susarsak konuşulabilir, sükûtla tepki verilebilir. Bu bir anlık susmanın çok şey ifade ettiği ender durumlardan biridir "Yüce" kategorisi, nasıl ki "alg1üstü”nü gösteriyorsa, susku da idrak/kavrayış ötesini gösterir. Zira "hakkında konuşulamayan" kavrama yetisinin sınırlarının ötesinde, Kant'ın deyişi ile "kendinde-şey" (Ding an sich) konumundadır. Bu durumda susku, bir şaşıp kalma, bir nutku kesilme, bir ifade edememe durumu değildir. Burada epistemolojik ve ontolojik bir sorun vardır: "Üzerine konuşulamayan" kavrama yetimiz, alg1 ve idrak sinırlarımızın ötesinde kalır.

Wittgenstein, Tractatus'da "suskuyu ebedi yurdu" hâline getirmiş gibi görünse de (Megill 1998: 401), bu suskunluğunu Felsefi Soruşturmalar'da "dil oyunları” ile bozar. Dili olgusal dünya, Kant'ın ifadesi ile fenomenlerle sınırlamak yerine gündelik hayattaki kullanımıyla anlamlandırınca, dil ve gerçeklik bağlantısının yeniden kurulması kaçınılmaz olur. Artık söz konusu olan bizzat "kendinde şey"in, sözgelimi Tanrı'nın ne ise o olarak kavranılması değil, insan dünyasındaki yeri ve anlamı çerçevesinde, gündelik dil ve anlam alanına girdiği şekliyle anlamaya çalışmaktır. Tıpkı Kant'ın Salt Aklın Eleştirisìnde, anlama yetisi (verstand) içinde kendisine yer bulamadığ 1 Tanrı'y1, giderek eti- 
ğin imkânı haline getirmesi ve sonunda "İnanca yer açmak için bilmeyi (das Wissen) bir yana bırakmak zorunda kaldım” demesinde olduğu gibi (1853: 27). Bir felsefi söylem olarak susku konusunda, son bir iki durağa daha uğrayabiliriz: Camus de, suskuyu, absürtün, uyumsuzluğun, varoluştaki irrasyonalitenin ilk belirtisi olarak görür. Bu görü, daha çok bir anlam yitimi şeklinde kendini gösterir ve şöyle der Camus:

Kimi durumda kişinin ne düşündüğü sorusuna "hiç" cevabını vermesi yapmacık olabilir. Ama buna karşılık içten bir cevapsa, boşluğun çok şey anlattığ1, günlük devinimler zincirinin koptuğu, yüreğin kendisini yeniden düğümleyecek bir halka arayıp da bulamadığı şu garip tinsel durumu belirtiyorsa, o zaman uyumsuzluğun ilk belirtisi gibidir. (1988: 22)

Camus'nün bir başka susku noktası da, varoluşsal belirsizliği ortadan kaldırmak için yüreğini bağlayacak bir düğüm noktası arayıp da bulamadığı, bir tür "kesinlik" arayışı durumunda ortaya çıkar:

Bilim, bu sihirli ve karmaşı evrenin atoma, atomun da elektronlara indirgendiğini öğretir insana. Gerisi elektronların bir çekirdek etrafinda toplandıkları görünmez bir gezegen takımından söz edilir. Dolayısıyla dünya, bir imge ile açıklanır. $\mathrm{O}$ zaman dönüp dolaşıp şiire geldiğimizi anlıyorum. Böylece, bana her şeyi öğretmesi gereken bilim varsayımda sona eriyor. Anliyorum; bilim yoluyla olguları kavrayıp sayabilsem de, dünyay1 kavrayamam. (1988: 28-29)

Böylece, modern felsefenin açık, net ve kesin bir dille konuşmaya eğilimli aklının, çağdaş dünyanın eşiğinde, yaşanan yıkımların da etkisiyle bir özgüven yitimine uğradığı ve aslında her şeyin o kadar kesin, açık ve net olmadığı yönünde bir sonuca ulaştığı söylenebilir.

\section{Sonuç}

İnsan dünyasında mutlak sessizlikten söz edilemez. Bilinç, değdiği her şeyi anlama tebdil eyler. Sartre şöyle der: "Yazar, bir şeyin sözünü etmekten kaç1nabilir. Ama susmak da bir sözdür. İnsan bir kez konuşmanın dünyasına girdi mi, susmak da sözcüklerle tanımlanır. Susma bir çeşit sözcük bağıntısıdır ve bir şeyi anlatır. Dilsizin sustuğu söylenebilir mi?” (1994: 26). Suskunun felsefi değerde olabilmesi için, yukarıda da ortaya çıktığı üzere, bir bağlam içinde görünmesi, bir konuşmanın devamı olması gerekir. Sükût, sözün ve söylemenin devamıdır. Bir tür cevap vermek, bir tür cevap beklemektir. Bu nedenle doğada sükût yoktur, sessizlik vardır. Suskunun olabilmesi için, sessizliğin bilince değmesi, zamanın bilinçle mayalanması gerekir. Bu nedenle insanın suskunluğu ile doğanın suskunluğu birbirinden farklıdır. Doğa sessizliktir ve konuşmaya niyetlenmez ama insanın konumu, konuşmak, dinlemek ve dile getirmek üzere kuruludur. Suskunun felsefi değerde olabilmesi için felsefi bir 
bağlamda ortaya çıkması, daha önceden konuşulmuş, sorulmuş ve cevaplanmış olması gerekir. Bu susku da felsefeye dâhildir. Öte yandan suskuyu sözün ve konuşmanın diline çevirecek, suskunun ne söylediğini anlayacak ve anlatacak kadar iyi bir dinleyicisinin de olması gerekir. Bağlamı, niyeti ve dinleyicisi olan bir susku, giderek felsefi değerde ortaya çıkar.

Son olarak şu soruyu sorabiliriz: Ebedi bir susku durumu olarak, ölüm de, felsefi söylemin içine girer mi? Eğer ölüme sorabilecek sorularımız varsa ve ondan gelen suskuyu gündelik dile çevirebilecek bir duyarlığımız ve dilbilgimiz varsa, bu da olabilir. Sözgelimi, ölümün felsefi bir değerde olabilmesi için şöyle bir soru karşısında ortaya çıkması gerekir. Ölüm insana ne yapar? Öldükten sonra "ben” dediğimiz bu şey, "benlik" ve "kişilik" dediğimiz bu yap1 ne olur, nereye gider? Bir kez öldükten sonra artık hep ölü müdür insan? Bu ve benzeri soruları soran her bir bireye ölüm, yeterince konuşur, onu yeterince eğitir, terbiye eder. Bu derin bilgeliğe sadece, Yunus'un deyişi ile "hece taşları"nda değil, varoluşun muhasebesini yapan, anlamını soran-sorgulayan her türlü konuşmada tanık olabiliriz. Şairin "Mürşî̀ ki dilersin sana yetmez mi ölüm?” mısrainda olduğu gibi (Demirbağ 1998: 22), sonlu bir beden içinde konumlanan insanı olgunlaştıran ve terbiye eden bir metin olarak ölüm, nihai hakikatlere ve gerçeklere sevdalı felsefe yolcularına çok şey vaat eder gibidir. Belki bunun için Platon, felsefeyi, "ölüm hakkında düşünmek" olarak tanımlamı̧, Topçu, "Nihayet ölüm, hepimize açılmış olan bir mekteptir" demişti (1998: 54). Gerçeği söylemek gerekirse, biz de bugün burada ölüm hakkında dilimiz döndüğünce konuşmakla ölümün ebedi suskunluğunu felsefenin diline tercüme etmeye çalışır gibi görünüyoruz. 


\section{Kaynaklar}

Augustine (1999). The Confessions of Augustine, Çev. Edward B. Pusey, New York: Modern Library.

Bozkurt, Nejat (1995). 20. Yüzyıl Düşünce Akımları, İstanbul: Sarmal Yayınevi. Camus, Albert (1988). Sisyphos Söyleni, Çev. Tahsin Yücel, İstanbul: Adam Yayınları. Demirbağ, Ömer (1998). "Gazel”, Seyir Estetik ve Sanat Dergisi 5-6, s.22.

Ferideddin-i Attar (1990). Mantık al-Tayr II, Çev. Abdulbaki Gölpınarlı, İstanbul: Milli Ĕ̆itim Bakanlığ1 Yayınları.

Kant, Immanuel (1853). Kritik der reinen Vernunft, Leipzig: Leopold Voss.

Kierkegaard, Søren (2002). Korku ve Titreme, Çev. İbrahim Kapalıkaya, İstanbul: Anka Yayınları.

Kranz, Walther (1984). Antik Felsefe, Çev. Suat Baydur, İstanbul: Sosyal Yayınlar.

Lucian (1919). Lucian II, Çev. A. M. Harmon, London: William Heinemann Press.

Megill, Allan (1998). Aşırılı̆̆ın Peygamberleri, Çev. Tuncay Birkan, Ankara: Bilim Sanat Yayınlar1.

Mevlâna (1988). Mesnevi II, Çev. Veled İzbudak, İstanbul: Milli Eğitim Bakanlığ1 Yayınlar1.

Platon (1989). Gorgias, Çev. Reyhan Erben, İstanbul: Milli Eğitim Bakanlığg1 Yayınlar1.

— (1990). Theaitetos, Çev. Macit Gökberk, İstanbul: Milli Eğitim Bakanlığı Yayınları.

Rilke, Rainer Maria (2014). Orpheus'a Soneler, Çev. Yüksel Özoğuz. İstanbul: Yap1 Kredi Yayınları.

Safa, Peyami (2000). Fatib-Harbiye, İstanbul: Ötüken Yayınları.

Sartre, Jean-Paul (1994). Denemeler, Çev. Sabahattin Eyüboğlu ve Vedat Günyol, İstanbul: Say Yayınları.

Schopenhauer, Arthur (1966). The World as Will and Representation, Vol. 1, Çev. E. F. J. Payne, New York: Dover Publications.

Topçu, Nurettin (1998). Türkiye’nin Maarif Davası, İstanbul: Dergâh Yayınları.

Wittgenstein, Ludwig (1961). Tractatus Logico-Philosophicus, Çev. D. F. Pears ve B. F. McGuinness, London: Routledge-Kegan Paul. 


\section{ABSTRACT \\ Silence as a Manner of Philosophical Discourse}

Philosophy always constructs itself on the action of saying, it realizes itself on it. We cannot even think of a silent philosophy and a philosophy that does not tend to say. State of silence, comes to the fore of philosophy at any time or another. The most advanced examples of this could be seen in Kant, Kierkegaard and Wittgenstein. These are such meaningful silences, that they are the most genuine answers almost given to the most fundamental questions of philosophy that is confronted. Especially when metaphysical subjects are in question -death is also included- it can be seen that philosophy is buried in deep waters of silence. The problem is that: Does silence end the speech, or start a new one? Is silence, really silence, or "a new start, a new sign, a new change" as Rilke pointed out? When we are silent does it mean that we have finished speaking, or else the real speech begins then? If silence is also a manner of talking, it can come out as a philosophical discourse. In this context another question can be asked: Does the everlasting silence that death brings, have philosophical value?

Keywords: Philosophy, discourse, silence, death 